\title{
Respiratory impedance in children with cystic fibrosis using forced oscillations in clinic
}

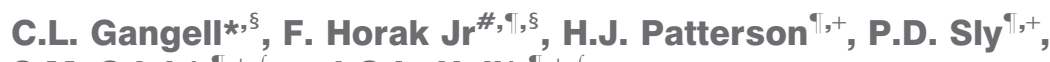 \\ S.M. Stick ${ }^{\star, \oplus,+, f}$ and G.L. Hall ${ }^{*, \oplus^{+},+, f}$
}

ABSTRACT: Measurement of lung function is an important component of clinical management in cystic fibrosis (CF), but has been difficult in young children. The present study aimed to characterise the utility of the forced oscillation technique for measurement of lung function in preschool-aged children with CF in a routine clinical setting.

Lung function was assessed in 56 young children (aged 2-7 yrs) with CF. Respiratory system resistance $(R \mathrm{rs})$ and reactance $(\mathrm{Xrs})$ at 6,8 and $10 \mathrm{~Hz}$ were measured and expressed as Z-scores. Children were classified as asymptomatic or symptomatic based on an administered respiratory questionnaire and physical examination at the time of testing. Between-test repeatability was assessed in 25 children.

Measurement of lung function using the forced oscillation technique was feasible in the CF clinic. The children with CF, as a group, had Z-scores for Rrs at $6 \mathrm{~Hz}(\operatorname{Rrs}, 6) \operatorname{Rrs}, 8, R r s, 10$, Xrs at $6 \mathrm{~Hz}$ $(X r s, 6)$ and $X_{r s, 8}$ that were significantly different from zero. Children with current symptoms showed significantly decreased Xrs and increased Rrs,6 compared with asymptomatic children.

Measurement of lung function using the forced oscillation technique is feasible in young children with cystic fibrosis in a clinical setting. The technique has the potential to improve knowledge concerning early cystic fibrosis lung disease.

KEYWORDS: Pulmonary function, reactance, repeatability, resistance, symptoms

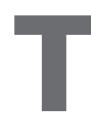
he onset of lung disease in cystic fibrosis (CF) occurs early in life, with changes in lung structure [1, 2] and function [3-6], as well as the presence of inflammation and infection [3, 5-7], in otherwise asymptomatic infants. During the preschool years, structural changes and abnormalities due to CF have been identified using high-resolution computed tomography (HRCT) $[1,8,9]$. Measurement of lung function is an integral component of the clinical management of older children and adults. Spirometry is commonly used to predict pulmonary exacerbations or track responses to therapy in older children; however, alternative techniques are required for routine use in younger children.

Alterations in the respiratory function of young children with CF have been demonstrated using the interrupter technique [10-12], multiple-breath wash-out method [13-14] and impulse oscillation system (IOS) [12, 15]. The forced oscillation technique (FOT) is a practical method for monitoring pulmonary function in young children that requires minimal patient cooperation
$[16,17]$. It provides information about both respiratory system resistance $(R \mathrm{rs})$ and apparent stiffness (or reactance $(X \mathrm{rs})$ ) that cannot be obtained using either the interrupter or multiplebreath wash-out techniques. The use of a FOT that employs pseudorandom noise (PRN) as a forcing signal may provide different information on respiratory dysfunction compared with the IOS, a variation of the FOT that uses an intermittent pressure impulse [18]. The present study focuses on a PRN oscillatory signal and the technique is referred to as the FOT unless otherwise stated.

Studies utilising the FOT in healthy young children have demonstrated that, at frequencies of $<10 \mathrm{~Hz}$, measurements of Rrs and $\mathrm{Xrs}$ are repeatable, with a mean coefficient of variation of $<10.2$ and $<20.5 \%$, respectively, and an SD between two measurements over a $15-\mathrm{min}$ period of $<1.3$ and $<1.0 \mathrm{hPa} \cdot \mathrm{L}^{-1} \cdot \mathrm{s}$, respectively [19-21]. However, repeatability might be different in children with respiratory diseases, and has not yet been studied in children with CF.
AFFILIATIONS

*School of Paediatrics and Child Health, and

+Telethon Institute for Child Health Research and Centre for Child Health Research, University of Western Australia, and

"Respiratory Medicine, Princess Margaret Hospital for Children, Perth, Australia.

\#Dept of Paediatric and Adolescent Medicine, Medical University of

Vienna, Vienna, Austria.

${ }^{\S}$ Both authors contributed equally to this article.

${ }^{f}$ Both senior authors contributed equally to this article.

\section{CORRESPONDENCE}

S.M. Stick

Respiratory Medicine Princess Margaret Hospital for Children G.P.O. Box D184

Perth Western Australia 6840

Australia

Fax:61 893408181

E-mail: Stephen.Stick@health.wa. gov.au

Received:

January 112007

Accepted after revision:

July 192007

SUPPORT STATEMENT

This study was supported by the University of Western Australia

(Perth, Australia), National Health and Medical Research Council (Canberra, Australia) and United States Cystic

Fibrosis Foundation (Bethesda, MD, USA). C. Gangell was supported by Cystic Fibrosis Australia (North Ryde, Australia). F. Horak was supported by a grant from the Austrian Science Fund (Vienna, Austria).

STATEMENT OF INTEREST

None declared.

European Respiratory Journal

Print ISSN 0903-1936

Online ISSN 1399-3003 
The aim of the present study was to determine the utility of using the FOT for the measurement of respiratory function in a young $\mathrm{CF}$ population in a routine clinical setting.

\section{METHODS}

\section{Patients}

Children with CF (aged 2-7 yrs; $n=56$ ) who underwent pulmonary function testing at the Princess Margaret Hospital for Children (Perth, Australia) as part of their clinical assessment participated in the present study. Diagnosis of CF was determined through newborn screening in 56\% of patients, respiratory symptoms in $9 \%$ and failure to thrive, meconium ileus or family history in the remaining $35 \%$. Diagnosis of CF was confirmed using the sweat test [22]. Parents gave written consent for their children to participate in the study, and the study was approved by the ethics committee of the Princess Margaret Hospital for Children.

\section{Protocol}

Assessment of the children, including height and weight measurements, was performed on the day of the respiratory function tests. Children were classified as being currently symptomatic or asymptomatic at the time of consultation through a validated questionnaire administered to parents with clinician comments [23]. Children were classified as currently symptomatic if a parent reported cough, sputum production or a current cold or showed signs of a lower respiratory tract infection detected by a paediatric respiratory physician. Children were classified as asymptomatic if free of respiratory symptoms and abnormal respiratory signs at the time of investigation.

Pulmonary infection data were obtained from the most recent bronchoalveolar lavage (BAL) performed as part of the routine annual assessment. Infection data were not used for 10 children as their BAL visit had been $>1 \mathrm{yr}$ before the FOT was performed, or the children had not undergone BAL.

Pulmonary function measurement was first attempted at the age of 2 yrs and then at every subsequent 3-monthly clinic visit in order to familiarise the children with the FOT. Once the children could produce at least three technically acceptable measurements in a single test session, measurements were recorded and retained.

\section{Forced oscillation technique}

Forced oscillatory measurements were performed according to European Respiratory Society recommendations [16], and as previously described by the authors' group [21]. Measurements of respiratory system input impedance $(\mathrm{Zrs})$ were obtained using a commercially available device (I2M; Chess Medical, Ghent, Belgium) based on the research equipment prototype described by LANDSER et al. [17]. Briefly, a loudspeaker-generated PRN forcing signal, containing integral multiple frequencies ranging $2-48 \mathrm{~Hz}$, was applied at the mouth of the child via a mouthpiece containing a $0.1-\mu \mathrm{m}$ pore-size bacterial filter (SureGard; Bird Healthcare, Melbourne, Australia). Mouth pressure and flow were recorded for $8 \mathrm{~s}$ per measurement at the airway opening, and Zrs spectra calculated from both the inspiratory and expiratory signals. Equipment accuracy was verified daily using known impedances, and the $\mathrm{Zrs}$ spectra were corrected for the impedance characteristics of the mouthpiece and bacterial filter.

The patient sat upright, wearing a nose-clip and breathing quietly through the mouthpiece. In order to minimise upper airway shunting, the patient's cheeks and lower jaw were supported by a technician. A minimum of three and maximum of seven measurements were collected from each child. Measurements were considered technically inadequate and excluded if three or more individual frequencies showed a coherence of $<0.95$, leak occurred around the mouthpiece, or physical artefacts such as a cough, swallow or glottis closure were detected. Technically acceptable corrected $Z$ rs spectra were analysed, and mean Rrs and $X r s$ at 6,8 and $10 \mathrm{~Hz}$ recorded. The aim was to obtain within-test variability of the Rrs of $<10 \%$. However, individual measurements and the subsequent averaged $Z$ rs data were not excluded if this criterion was not met.

In order to determine the between-test repeatability, a second set of measurements was recorded 15 min after the first set in a subgroup of children $(n=25)$.

\section{Statistical analysis}

Data are presented as mean \pm SD and were normally distributed unless otherwise stated. Differences between symptom groups were analysed using the Mann-Whitney rank-sum test. The coefficient of repeatability (1.96SD of difference between two measurements) was calculated for tests performed $15 \mathrm{~min}$ apart according to the methods of BLAND and ALTMAN [24], and comparison between symptom groups analysed using an independent unpaired t-test.

Baseline respiratory function (Rrs and $\mathrm{Xrs}$ ) was expressed as Zscores, calculated from reference values derived from a local population of 158 healthy preschool children, aged 2-7 yrs, in whom Zrs was measured using an identical FOT protocol [21]. This group of healthy children had not had doctor-diagnosed or parentally reported wheeze or asthma at any time during their life and had had no acute respiratory infections within the previous 3 weeks and is described in detail elsewhere [21]. Zscores were not calculated in children with CF with a height of $<92 \mathrm{~cm}$ as this was the lower limit in the healthy population. The test of BARTLETT [25] was used to determine whether children with CF exhibited altered respiratory function compared to the healthy reference population.

\section{RESULTS}

Details of the study population are given in table 1 . There were no significant differences in age, height or weight between children classified as currently asymptomatic or currently symptomatic.

\section{Repeatability}

The between-measurement repeatability of $\operatorname{Rrs}$ and Xrs are shown in table 2.

No systematic bias in between-test repeatability was observed for Rrs or Xrs (fig. 1). Absolute and relative differences in lung function between tests were not dependent upon mean lung function, height or age using univariate modelling. The coefficient of repeatability between tests was $<2.5 \mathrm{hPa} \cdot \mathrm{L}^{-1} \cdot \mathrm{s}$ for $R \mathrm{rs}$ and $<1.5 \mathrm{hPa} \cdot \mathrm{L}^{-1} \cdot \mathrm{s}$ for $X \mathrm{rs}$, equating to a difference of 


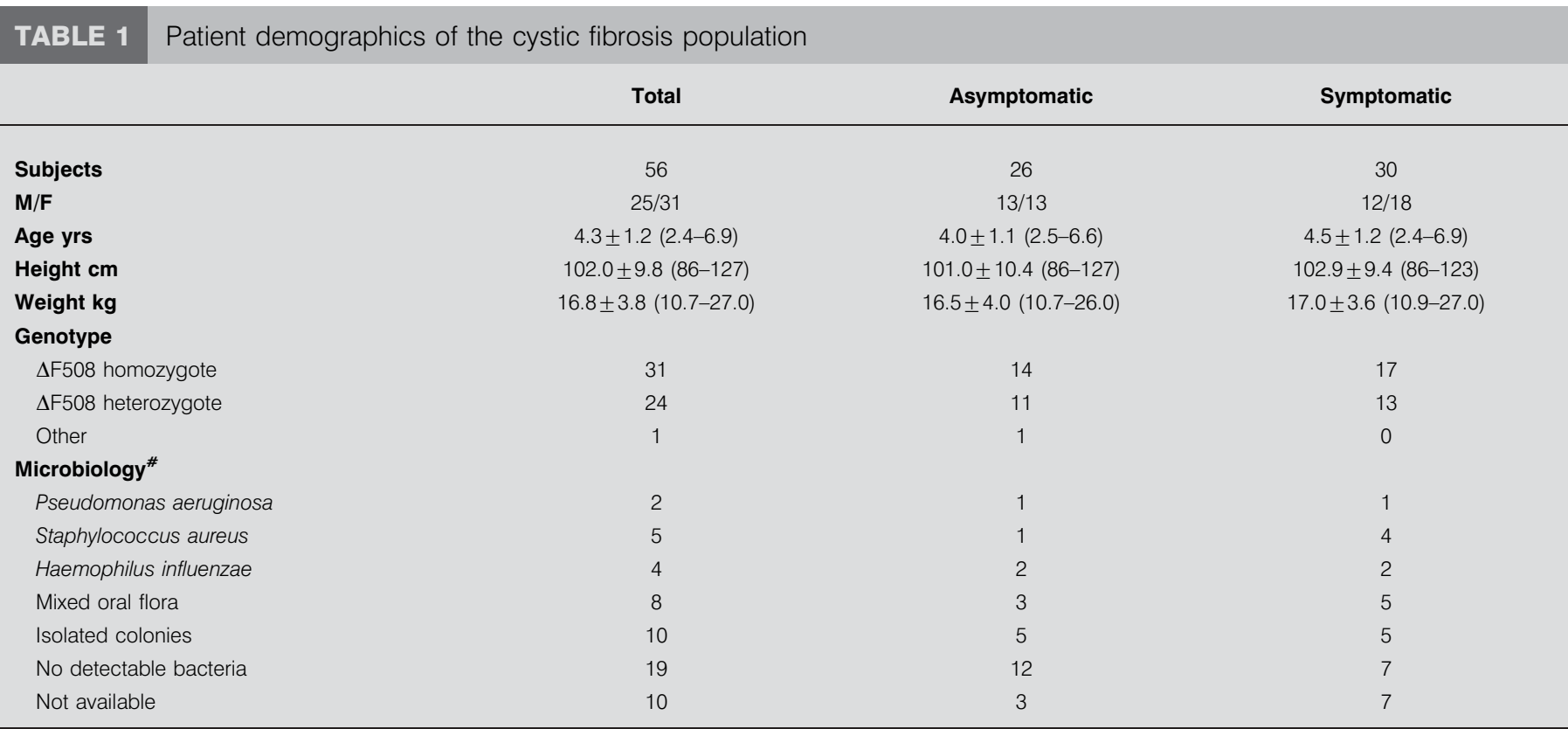

Data are presented as $n$ or mean \pm SD (range). M: male; F: female; $\Delta F 508$ : deletion of phenylalanine 508 of the cystic fibrosis transmembrane conductance regulator \#: results from last bronchoalveolar lavage (individual named pathogens were identifed on the basis of $>1 \times 10^{4}$ colony-forming units (cfu) $\mathrm{mL}^{-1}$; isolated colonies were identified on the basis of $<1 \times 10^{4} \mathrm{cfu} \cdot \mathrm{mL}^{-1}$ ).

$<3 \%$ for $\operatorname{Rrs}$ and $<13 \%$ for Xrs (table 2 ). Repeatability was not affected by the presence of respiratory symptoms (data not shown).

\section{Respiratory function}

Z-scores were calculated for 53 (out of 56) children with a height of $>92 \mathrm{~cm}$. The distribution of respiratory function in children with $\mathrm{CF}$ relative to the healthy reference population is shown in figure 2 . Technically acceptable measurements were obtained, on average, after two or three visits. As a group, children with CF showed significantly increased Rrs compared with the healthy reference population, with Z-scores for Rrs at
$6 \mathrm{~Hz}(\operatorname{Rrs}, 6 ; \mathrm{p}<0.001), R \mathrm{rs}, 8(\mathrm{p}<0.001)$ and $R \mathrm{rs}, 10(\mathrm{p}<0.001)$ that were significantly different from zero (table 3 ). Even when children were classified as asymptomatic at the time of testing $(\mathrm{n}=24)$, the Z-scores for $\operatorname{Rrs}, 8(\mathrm{p}<0.02)$ and $R \mathrm{rs}, 10(\mathrm{p}<0.05)$ were significantly increased from zero.

When compared with the healthy population, the Z-scores for $X \mathrm{rs}$ in children with $\mathrm{CF}$ as a group were significantly different from zero for $X r s$ at $6 \mathrm{~Hz}(X \mathrm{rs}, 6 ; p<0.001)$ and $X r s, 8(p=0.01)$, but not for $X r s, 10 \quad(p=0.09$; table 3$)$. These differences were primarily due to the children who were symptomatic at the time of testing (table 3).
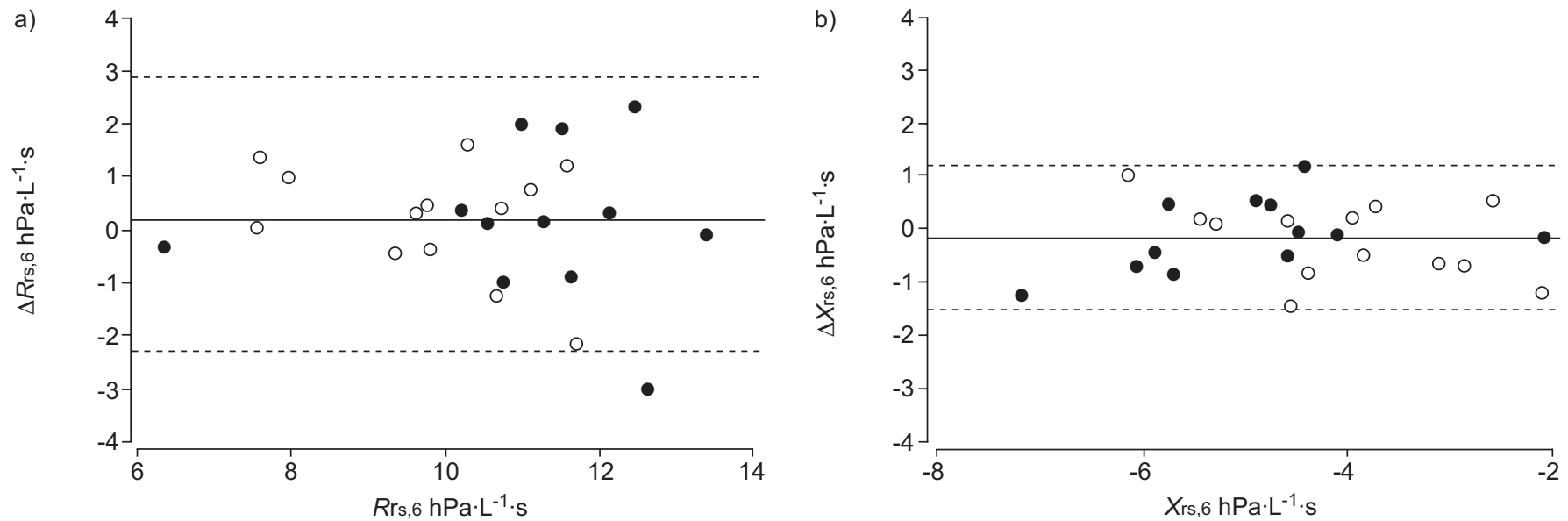

FIGURE 1. Bland-Altman plots of: a) respiratory system resistance at $6 \mathrm{~Hz}(\mathrm{Rrs}, 6)$; and b) respiratory system reactance at $6 \mathrm{~Hz}\left(\mathrm{Xrs}_{\mathrm{rs}} 6\right)$ for two sets of mean forced oscillation measurements made 15 min apart in children with cystic fibrosis in the absence $(\bigcirc)$ or presence $(\bullet)$ of respiratory symptoms $(\longrightarrow$ : mean difference; -----: limits of agreement). $\Delta$ : change. 


\begin{tabular}{|c|c|c|c|}
\hline \multirow[t]{3}{*}{ TABLE 2} & \multicolumn{3}{|c|}{$\begin{array}{l}\text { Between-measurement repeatability of } \\
\text { respiratory system resistance }(R r s) \text { and } \\
\text { reactance (Xrs) in young chilren with cystic } \\
\text { fibrosis }\end{array}$} \\
\hline & \multicolumn{2}{|c|}{ Difference } & \multirow[t]{2}{*}{ Coefficient of repeatability } \\
\hline & $\begin{array}{l}\text { Absolute } \\
\mathrm{hPa} \cdot \mathrm{L}^{-1} \cdot \mathrm{s}\end{array}$ & $\begin{array}{c}\text { Relative } \\
\%\end{array}$ & \\
\hline Rrs,6 & $0.18 \pm 1.25$ & $2.0 \pm 11.2$ & \pm 2.46 \\
\hline Rrs,8 & $0.18 \pm 1.08$ & $2.0 \pm 10.1$ & \pm 2.12 \\
\hline Rrs, 10 & $0.27 \pm 1.07$ & $2.6 \pm 10.6$ & \pm 2.10 \\
\hline Xrs,6 & $-0.16 \pm 0.70$ & $4.7 \pm 18.1$ & \pm 1.36 \\
\hline Xrs,8 & $-0.28 \pm 0.67$ & $9.5 \pm 27.2$ & \pm 1.31 \\
\hline Xrs, 10 & $-0.34 \pm 0.74$ & $12.7 \pm 29.8$ & \pm 1.45 \\
\hline
\end{tabular}

Data are presented as mean $\pm \mathrm{SD}$, unless otherwise stated. Rrs,6: Rrs at $6 \mathrm{~Hz}$; $\mathrm{Xrs}_{\mathrm{rs}} 6 \mathrm{Xrs}$ at $6 \mathrm{~Hz}$

\section{DISCUSSION}

In the present study, respiratory function was measured in 56 young children with CF using the FOT in a routine clinical setting, and it was demonstrated that these children showed increased Rrs and reduced Xrs compared to a healthy reference population [21]. The test was easy to perform and feasible within the clinical setting. Children with current symptoms showed an increased Rrs,6 and lower $X_{r s}$ (at $6-10 \mathrm{~Hz}$ ) compared to children who were asymptomatic at the time of testing. The between-test repeatability in young children with CF was similar to that previously reported in healthy preschool-aged children [21].

\section{Between-test repeatability}

The present study characterised the repeatability of betweentest measurements over a $15-\mathrm{min}$ period in a young $\mathrm{CF}$ population, with the SD of changes for $\operatorname{Rrs}\left(1.07-1.25 \mathrm{hPa} \cdot \mathrm{L}^{-1} \cdot \mathrm{s}\right)$ and $X \mathrm{rs}\left(0.67-0.74 \mathrm{hPa} \cdot \mathrm{L}^{-1} \cdot \mathrm{s}\right)$ lying within the ranges of shortterm repeatability previously reported for $\operatorname{Rrs}(0.55$ $\left.1.41 \mathrm{hPa} \cdot \mathrm{L}^{-1} \cdot \mathrm{s}\right)$ and $\mathrm{Xrs}\left(0.57-1.21 \mathrm{hPa} \cdot \mathrm{L}^{-1} \cdot \mathrm{s}\right)$ in healthy children [19-21, 26, 27]. In the present study, between-test repeatability

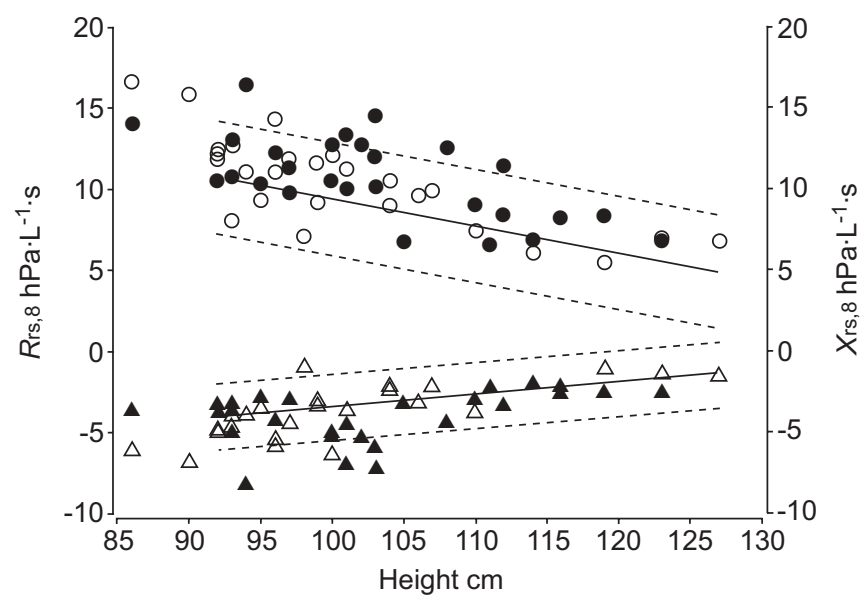

FIGURE 2. Distribution of respiratory system resistance at $8 \mathrm{~Hz}(\operatorname{Rrs}, 8 ; 0$, and respiratory system reactance at $8 \mathrm{~Hz}\left(\mathrm{Xrs}_{\mathrm{rs}, 8}, \Delta, \boldsymbol{\Delta}\right)$ in 56 children with cystic fibrosis, when asymptomatic $(\bigcirc, \triangle)$ or symptomatic (ด. $\boldsymbol{\Delta})$, compared with a healthy reference population. _— $95 \%$ confidence interval.

was not influenced by symptoms, which suggests that, in young children with $\mathrm{CF}$, short-term repeatability may not be a function of disease, history or status.

\section{Respiratory function}

As a group, children with CF exhibited significantly worse lung function, with higher Rrs at 6, 8 and $10 \mathrm{~Hz}$ and lower $\mathrm{Xrs}$ at 6 and $8 \mathrm{~Hz}$ than a healthy reference population. However, most children with $\mathrm{CF}$ showed pulmonary function within the normal range, as defined by being within 2SD ( \pm 2 Z-scores) of the mean of the healthy reference population (fig. 2). These data are consistent with previous reports in children with $\mathrm{CF}$ using the interrupter technique [10], multiple-breath wash-out method [14] and IOS [12, 15]. The fact that the majority of children with $\mathrm{CF}$ fall into the normal range is not surprising, since, in general, these children exhibited mild disease, with $<5 \%$ of children presenting to clinic with respiratory signs of wheeze, crackles or respiratory tract infection. Some children did show abnormal lung function; $13 \%$ had a $R r s, 8$ and $17 \%$ a $X \mathrm{rs}, 8$ outside the normal range. This increased to $21 \%$ outside normal for both $R \mathrm{rs}, 8$ and $X \mathrm{rs}, 8$ in children with CF who were

TABLE 3 Z-scores for respiratory system resistance (Rrs) and reactance $\left(X_{\mathrm{rs}}\right)^{\#}$ in children with cystic fibrosis

\begin{tabular}{|c|c|c|c|c|}
\hline & Total & Asymptomatic & Symptomatic & p-value \\
\hline Subjects $n$ & 53 & 24 & 29 & \\
\hline Rrs,8 & $0.73 \pm 1.05^{\star \star \star}$ & $0.46 \pm 0.92^{+}$ & $0.96 \pm 1.11^{\star \star *}$ & 0.09 \\
\hline Rrs, 10 & $0.63 \pm 1.07^{\star \star \star}$ & $0.41 \pm 0.92^{*}$ & $0.82 \pm 1.16^{\star \star *}$ & 0.17 \\
\hline Xrs,6 & $-0.71 \pm 1.16^{\star \star \star}$ & $-0.27 \pm 0.90$ & $-1.08 \pm 1.25^{\star \star \star}$ & 0.01 \\
\hline
\end{tabular}

Data are presented as mean $\pm \mathrm{SD}$, unless otherwise stated. Rrs,6: Rrs at $6 \mathrm{~Hz} ; \mathrm{Xrs}_{\mathrm{rs}}$ : $\mathrm{Xrs}_{\mathrm{rs}}$ at $6 \mathrm{~Hz}$. ${ }^{*}$ : using the forced oscillation technique. ": asymptomatic versus symptomatic. ${ }^{+}: p<0.02 ;{ }^{*}: p<0.05 ;{ }^{* *}: p<0.01 ;{ }^{* *}: p<0.001$ versus healthy children. 
classified as symptomatic. This suggests that measurements outside the normal range may be indicative of clinically relevant disease. As measurements of pulmonary function were performed as part of the routine clinical assessment of children with $\mathrm{CF}$, children were measured as they presented to the clinic. Lung function testing is used as part of the clinical assessment of children with CF.

Evidence in the literature demonstrates that lung disease begins in the periphery in young children with CF. Structural changes to the parenchyma in CF have been identified in infancy and early childhood using HRCT [1, 2, 9]. Likewise, the presence of inflammation in otherwise asymptomatic individuals has been reported in young children with $\mathrm{CF}[3,6,7]$. The relationship between inflammation and tissue damping, which is reflective of respiratory tissue mechanics, has previously been shown in preschool children with CF [6].

The association between respiratory symptoms and abnormal lung function becomes more apparent in older children with $\mathrm{CF}$, possibly representing the progression of lung disease with age [28]. The studies in infants with CF of BRENNAN et al. [6] and RANGANATHAN et al. [4] both reported no associations with the presence or history of respiratory symptoms. Although children in this age group generally exhibit mild lung disease, and were well enough to undergo general anaesthesia in these studies, an association between a history of CF-related symptoms and worsening lung function, measured using the interrupter technique, has been reported in preschool children who were asymptomatic at the time of testing [10]. However, it should be noted that the group of children with a history of CF-related symptoms was considerably smaller $(n=8)$ than the group of children without symptoms $(n=31)$, which may have affected the outcome. The present study measured the respiratory function of children with $C F$ as part of the children's clinical assessment during routine clinic visits. At the time of clinical assessment, the present study demonstrated that children with current symptoms showed decreased Xrs (at 6-10 Hz) and increased Rrs,6 compared to children who were asymptomatic at the time of testing. Although this association suggests potential for increasing the available clinical information, longitudinal assessments are required in order to determine the magnitude of clinically relevant changes in FOT-derived variables in individual children.

\section{CONCLUSION}

The present study shows the results of lung function measures using the forced oscillation technique in a typical clinical population of preschool children with cystic fibrosis. It was demonstrated that lung function is reduced in this group compared to a healthy reference group, and that children with cystic fibrosis with current symptoms show reduced lung function compared to children with cystic fibrosis who are asymptomatic. Measurements of lung function are an important aid to the clinical management of cystic fibrosis in older children. Further studies are required in order to characterise clinically relevant changes in forced oscillation technique variables and to determine the role of measurement of lung function using the forced oscillation technique in the clinical management of preschool children with cystic fibrosis.

\section{ACKNOWLEDGEMENTS}

The authors would like to thank the paediatric respiratory medicine clinicians and E. Balding for their assistance in completing symptom questionnaires, and T. Fukushima, K. Udomittipong, M. Verheggen, J. Oostryck and V. Starveska for their assistance in measuring lung function.

\section{REFERENCES}

1 Long FR, Williams RS, Castile RG. Structural airway abnormalities in infants and young children with cystic fibrosis. J Pediatr 2004; 144: 154-161.

2 Martinez TM, Llapur CJ, Williams TH, et al. Highresolution computed tomography imaging of airway disease in infants with cystic fibrosis. Am J Respir Crit Care Med 2005; 172: 1133-1138.

3 Dakin CJ, Numa AH, Wang H, Morton JR, Vertzyas CC, Henry RL. Inflammation, infection, and pulmonary function in infants and young children with cystic fibrosis. Am J Respir Crit Care Med 2002; 165: 904-910.

4 Ranganathan SC, Stocks J, Dezateux C. The evolution of airway function in early childhood following clinical diagnosis of cystic fibrosis. Am J Respir Crit Care Med 2004; 169: 928-933.

5 Rosenfeld M, Gibson RL, McNamara S, et al. Early pulmonary infection, inflammation, and clinical outcomes in infants with cystic fibrosis. Pediatr Pulmonol 2001; 32: 356-366.

6 Brennan S, Hall GL, Horak F, et al. Correlation of forced oscillation technique in preschool children with cystic fibrosis with pulmonary inflammation. Thorax 2005; 60: 159-163.

7 Armstrong DS, Grimwood K, Carlin JB, et al. Lower airway inflammation in infants and young children with cystic fibrosis. Am J Respir Crit Care Med 1997; 156: 1197-1204.

8 Stiglbauer R, Schurawitzki H, Eichler I, Vergesslich KA, Gotz M. High resolution CT in children with cystic fibrosis. Acta Radiol 1992; 33: 548-553.

9 Marchant JM, Masel JP, Dickinson FL, Masters IB, Chang AB. Application of chest high-resolution computer tomography in young children with cystic fibrosis. Pediatr Pulmonol 2001; 31: 24-29.

10 Beydon N, Amsallem F, Bellet M, et al. Pulmonary function tests in preschool children with cystic fibrosis. Am J Respir Crit Care Med 2002; 166: 1099-1104.

11 Lebecque P, Stanescu D. Respiratory resistance by the forced oscillation technique in asthmatic children and cystic fibrosis patients. Eur Respir J 1997; 10: 891-895.

12 Nielsen KG, Pressler T, Klug B, Koch C, Bisgaard H. Serial lung function and responsiveness in cystic fibrosis during early childhood. Am J Respir Crit Care Med 2004; 69: 1209-1216.

13 Gustafsson PM, Aurora P, Lindblad A. Evaluation of ventilation maldistribution as an early indicator of lung disease in children with cystic fibrosis. Eur Respir J 2003; 22: 972-979.

14 Aurora P, Bush A, Gustafsson P, et al. Multiple-breath washout as a marker of lung disease in preschool children with cystic fibrosis. Am J Respir Crit Care Med 2005; 171: 249-256. 
15 Hellinckx J, De Boeck K, Demedts M. No paradoxical bronchodilator response with forced oscillation technique in children with cystic fibrosis. Chest 1998; 113: 55-59.

16 Oostveen E, MacLeod D, Lorino H, et al. The forced oscillation technique in clinical practice: methodology, recommendations and future developments. Eur Respir J 2003; 22: 1026-1041.

17 Landser FJ, Nagels J, Demedts M, Billiet L, van de Woestijne KP. A new method to determine frequency characteristics of the respiratory system. J Appl Physiol 1976; 41: 101-106.

18 Hellinckx J, Cauberghs $M$, De Boeck K, Demedts $M$. Evaluation of impulse oscillation system: comparison with forced oscillation technique and body plethysmography. Eur Respir J 2001; 18: 564-570.

19 Klug B, Bisgaard H. Specific airway resistance, interrupter resistance and respiratory impedance in healthy children aged 2-7 years. Pediatr Pulmonol 1998; 25: 322-331.

20 Malmberg LP, Pelkonen A, Poussa T, Pohjanpalo A, Haahtela T, Turpeinen M. Determinants of respiratory system input impedance and bronchodilator response in healthy Finnish preschool children. Clin Physiol Funct Imaging 2002; 22: 64-71.
21 Hall GL, Sly PD, Fukushima T, et al. Respiratory function in healthy young children using forced oscillations. Thorax 2007; 62: 521-526.

22 Gibson L, Cooke R. A test for concentration of electrolytes in sweat in cystic fibrosis of the pancreas utilizing pilocarpine by iontophoresis. Pediatrics 1959; 23: 545-549.

23 Gangell CL, Stick SM. Development of a symptom specific questionnaire for 2 to 7 year old children with cystic fibrosis. Respirology 2007; 12: Suppl. 1, S66.

24 Bland JM, Altman DG. Statistical methods for assessing agreement between two methods of clinical measurement. Lancet 1986; 1: 307-310.

25 Bartlett MS. Properties of sufficiency and statistical tests. Proc Math Phys Eng Sci 1937; 160: 268-282.

26 Bisgaard H, Klug B. Lung function measurement in awake young children. Eur Respir J 1995; 8: 2067-2075.

27 Hellinckx J, De Boeck K, Bande-Knops J, van der Poel M, Demedts M. Bronchodilator response in 3-6.5 years old healthy and stable asthmatic children. Eur Respir J 1998; 12: 438-443.

28 Farrell PM, Li Z, Kosorok MR, et al. Longitudinal evaluation of bronchopulmonary disease in children with cystic fibrosis. Pediatr Pulmonol 2003; 36: 230-240. 